\title{
Adult Mammalian Forebrain Ependymal and Subependymal Cells Demonstrate Proliferative Potential, but only Subependymal Cells Have Neural Stem Cell Characteristics
}

\author{
Bernard J. Chiasson, Vincent Tropepe, Cindi M. Morshead, and Derek van der Kooy \\ Neurobiology Research Group, Department of Anatomy and Cell Biology, University of Toronto, Toronto, \\ Canada, M5S 1 A8
}

\begin{abstract}
The adult derivatives of the embryonic forebrain germinal zones consist of two morphologically distinct cell layers surrounding the lateral ventricles: the ependyma and the subependyma. Cell cycle analyses have revealed that at least two proliferating populations exist in this region, one that is constitutively proliferating and one that is relatively quiescent and thought to include the endogenous adult neural stem cells. Earlier studies demonstrated that specific dissection of the region surrounding the lateral ventricles was necessary for the in vitro isolation of multipotent, self-renewing neural stem cells. However, in these studies, the ependymal layer was not physically separated from the subependymal layer to identify the specific adult laminar localization of the neural stem cells around the lateral ventricles. To determine which cellular compartment in the adult forebrain contained the neural stem cells, we isolated and cultured the
\end{abstract}

The developing mouse forebrain germinal zone is composed of two mitotically active cell populations: the ventricular zone (VZ) and the subventricular zone (SVZ). Although both proliferative regions harbor progenitor cells that mostly undergo radial migration away from the germinal zone during development, the adult derivatives of the VZ and SVZ are differentially fated. The neuroepithelial cells of the VZ, which are the first to emerge during histogenesis, are located adjacent to the ventricular lumen and are thought to terminally differentiate perinatally into cuboidal epithelial cells of the ependymal lining (Takahashi et al., 1996). The undifferentiated cells of the SVZ, which are derived from the VZ embryonically (Reznikov et al., 1997), are considered to persist as a thin layer of undifferentiated cells throughout adulthood, referred to as the subependyma (Sturrock and Smart, 1980; Takahashi et al., 1996). Furthermore, some cells located in or near the subependyma continue to proliferate throughout life (Smart, 1961; Morshead and van der Kooy, 1992; Kuhn et al., 1996; Tropepe et al., 1997), with the potential to generate new neurons and glia (Reynolds and Weiss, 1992; Richards et al., 1992; Lois and Alvarez-Buylla, 1993; Luskin, 1993; Morshead et al., 1994; Craig et al., 1996; Doetsch and Alvarez-Buylla, 1996).

\footnotetext{
Received Nov. 2, 1998; revised March 15, 1999; accepted March 22, 1999.

This work was supported by the Multiple Sclerosis Society of Canada, Medical Research Council (MRC) and National Centres of Excellence postdoctoral fellowships to B.J.C, an MRC postdoctoral fellowship to C.M.M., and an MRC doctoral research award to V.T. We thank Brenda Coles and Esther Galindo for excellent technical assistance.

Correspondence should be addressed to Dr. van der Kooy at the above address.

Dr. Chiasson's present address: Novartis Pharmaceuticals Canada Inc., 790 Bay Street, Toronto, Canada M5G 1N8.

Copyright (C) 1999 Society for Neuroscience 0270-6474/99/194462-10\$05.00/0
}

ependyma separately from the subependyma and tested for the presence of neural stem cells using the in vitro neurosphere assay. We demonstrate that the ependymal cells can proliferate in vitro to form sphere-like structures. However, the ependymal cells generating spheres do not have the ability to self-renew (proliferate to form secondary spheres after dissociation) nor to produce neurons, but rather only seem to generate glial fibrillary acidic protein-positive ependymal cells when plated under differentiation conditions in culture. On the other hand, a subpopulation of subependymal cells do possess the selfrenewing and multipotential characteristics of neural stem cells. Therefore, the adult forebrain neural stem cell resides within the subependymal compartment.

Key words: ependyma; subependyma; neural stem cells; proliferation; adult; forebrain
Thus, the remnant of the embryonic germinal zone in the adult forebrain is a heterogeneous constellation of differentiated and undifferentiated cells with varying proliferative capacities.

Cell cycle analyses of the proliferative population residing near the ventricle in the adult mouse forebrain have revealed that there are at least two distinct groups of cells. One population, the constitutively proliferating population, has a cell cycle time of $12.7 \mathrm{hr}$ (Morshead and van der Kooy, 1992). The other population, which has a relatively long cell cycle ( $\sim 15 \mathrm{~d}$ or more), is known as the relatively quiescent cell population (Morshead et al., 1994; Morshead et al., 1998). It has been demonstrated that the constitutively proliferating cells are the progeny of the relatively quiescent population (Morshead et al., 1994). Furthermore, this quiescent cell population proliferates in response to growth factors in vitro to give rise to clonal cell aggregates (neurospheres) containing neuronal and glial progenitor cells and thus are thought to represent the endogenous neural stem cell population (Reynolds and Weiss, 1992; Morshead et al., 1994; Craig et al., 1996). However, light and electron microscopic analyses of the cells surrounding the adult lateral ventricle suggests that there are at least five distinct populations of cells (some of which are relatively nonproliferative) based on morphological, cell cycle, and immunocytochemical parameters (Doetsch et al., 1997). It is not clear, therefore, which of the relatively quiescent mitotic cells previously identified represent the endogenous neural stem cells.

Ciliated ependymal cells are believed to be terminally differentiated, although some ependymal cell proliferation may occur after brain injury (for review, see Bernstein, 1986; Sarnat, 1995). Interestingly, ependymal cells express high levels of the intermediate filament protein nestin (Doetsch et al., 1997), currently the 


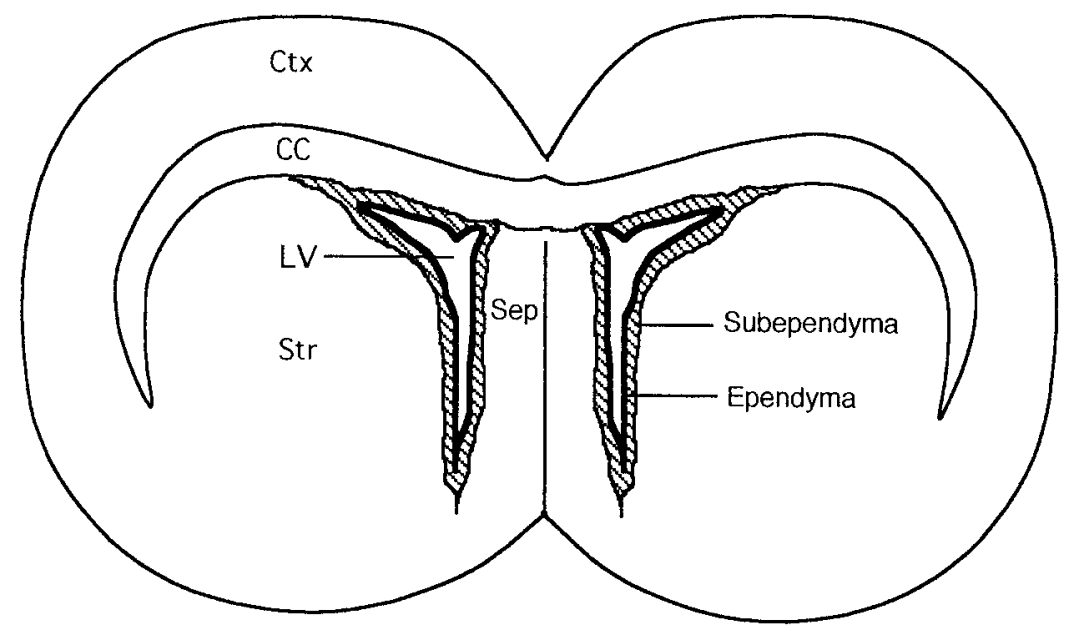

Figure 1. Schematic representation of a coronal section though the forebrain of the adult mouse showing the ependyma (thick black line) lining of the lateral ventricles $(L V)$ surrounded by the subependyma (cross-hatched area). Dissections of the ependyma and/or subependyma were performed on the medial wall closest to the septum (Sep). $C C$, Corpus callosum; Ctx, cortex; Str, striatum. best marker for neural stem and progenitor cells (Lendahl et al., 1990), as well as perhaps receptors for FGF2 and epidermal growth factor (EGF) (Matsuo et al., 1994; Craig et al., 1996), two mitogens that have been used extensively to study neural stem cell proliferation. Given that ependymal cells may be competent to respond to EGF and FGF2, it is possible that the ependyma contains the population of quiescent neural stem cells in vivo. In previous in vitro studies, the ependyma was not removed from the subependymal compartment at dissection, and so it remained conceivable that many or all of the sphere-forming stem cells isolated in vitro may have resided within the ependymal layer. Thus, we examined whether neural stem cells may be isolated from either of the ependymal and/or subependymal populations (Fig. 1).

\section{MATERIALS AND METHODS}

Separating the ependyma from the subependyma. To determine whether the ependymal layer could be reliably removed without contamination from other cell types, the following methods were applied. Adult male CD1 mice (25-30 gm; Charles River, Quebec, Canada) were given five injections of bromodeoxyuridine (BrdU) $(120 \mathrm{mg} / \mathrm{kg}$, i.p.; Sigma, St. Louis, MO) every $2 \mathrm{hr}$, and then $2 \mathrm{hr}$ after the last injection they were killed by cervical dislocation and their brains were removed (this particular schedule of mitotic labeling will identify the constitutively proliferating population within the subependyma but not ependymal cells) (for review, see Morshead and van der Kooy, 1992; Doetsch et al., 1997). The cerebrum was dissected free and was immediately placed (rostral end facing up) in a $35 \mathrm{~mm}$ Petri dish (one brain per dish). The brains were then covered with a $1 \%$ solution of low-melting point agarose at $38-40^{\circ} \mathrm{C}$ and then immediately placed in $4^{\circ} \mathrm{C}$ to harden the agarose solution. This provided a firm substrate, which allowed for easy sectioning of the brain on a vibratome. The brain was cut in ice-cold $0.9 \%$ saline using a vibratome to generate $400 \mu \mathrm{m}$ coronal sections. Two to three sections corresponding to anteroposterior coordinates from 1.20 to $0 \mathrm{~mm}$ relative to bregma (Franklin and Paxinos, 1997) were taken from each brain and placed into oxygenated artificial CSF (aCSF) containing (in mM): 124 $\mathrm{NaCl}, 5 \mathrm{KCl}, 1.3 \mathrm{MgCl}_{2}, 2 \mathrm{CaCl}_{2}, 26 \mathrm{NaHCO}_{3}$, and 10 D-glucose. Using surgical instruments and 30 ga syringe needles, the ependymal layer on the surface of the septal side from one hemisphere was dissected and mounted onto a coated slide (dissections from the striatal side of the brain were tried but could not be performed as easily without contamination from the subependyma, and therefore all data presented are from the septal side).

For the long-term BrdU labeling, animals $(n=3)$ were allowed to drink water containing $0.06 \mathrm{M} \mathrm{BrdU}$ (plus $0.3 \%$ saccharin) in their home cage for $7 \mathrm{~d}$. After this time, animals were allowed to survive for $31 \mathrm{~d}$ (assuming that only relatively quiescent cells will be labeled after $31 \mathrm{~d}$, with the other faster cycling cells having diluted-out the BrdU label) (Morshead et al., 1994) and then killed and perfused (with $4 \%$ paraformaldehyde and $0.4 \%$ picric acid in $0.16 \mathrm{~m}$ phosphate buffer, $\mathrm{pH} 6.9$ )
(Zamboni and de Martino, 1967), and the brains were removed and cryoprotected with $10 \%$ sucrose overnight. Coronal cryosections (6 or 14 $\mu \mathrm{m})$ were obtained and used for immunohistochemistry.

Immunocytochemistry. Several small pieces of ependyma, dissected from the septal side ipsilaterally, were placed onto a single slide and fixed for $5 \mathrm{~min}$ (as above). The fixative was then washed with $0.1 \mathrm{~m} \mathrm{PBS,} \mathrm{and}$ the tissue was frozen at $-20^{\circ} \mathrm{C}$ and subsequently processed for immunocytochemistry for both BrdU (rat monoclonal anti-BrdU, 1:100; SeraLab, London, UK) and S- $100 \beta$ (mouse anti-S-100 $\beta, 1: 500$; Sigma), which labels ependymal cells but not subependymal cells (Craig et al., 1996). Immunocytochemistry was performed as described previously by Craig et al. (1996). The $400 \mu \mathrm{m}$ coronal tissue sections that remained after the ipsilateral dissection of the ependyma from the septal portion of the lateral ventricle, together with the contralateral side of the sections containing the intact ependyma and subependyma, were then cryosectioned at $-20^{\circ} \mathrm{C}$ at a thickness of 6 or $14 \mu \mathrm{m}$ to be processed for both BrdU and S- $100 \beta$ immunostaining as described above. After immunostaining, all the tissue was stained with Hoechst 33258 nuclear stain $(0.015 \mathrm{mg} / \mathrm{ml}$ stock solution diluted to $0.001 \mathrm{mg} / \mathrm{ml}$; Boehringer Mannheim, Indianapolis, IN) for $20 \mathrm{~min}$ at room temperature. Immunostaining for differentiated, sphere-derived cells (on coverslips; see below) was performed as described by Reynolds and Weiss (1992). Briefly, coverslips were fixed in $4 \%$ paraformaldehyde (in PBS), $\mathrm{pH} 7.2$, for $30 \mathrm{~min}$ at room temperature, followed by three (5 min each) washes in PBS, pH 7.2. Cells were permeabilized for $5 \mathrm{~min}$ in PBS containing $0.3 \%$ Triton $\mathrm{X}-100$, rinsed for $5 \mathrm{~min}$ (two times) in PBS, and blocked for $20 \mathrm{~min}$ in PBS containing $10 \%$ normal goat serum (NGS). After blocking, coverslips were incubated in anti-microtubule-associated protein (MAP2) mouse monoclonal (IgG) (1:1000; Boehringer Mannheim) and anti-GFAP rabbit polyclonal (IgG) (1:1000; Chemicon, Temecula, CA) antibodies diluted in PBS containing $10 \%$ NGS overnight at $4^{\circ} \mathrm{C}$. Coverslips were then rinsed in PBS (three times) and subsequently incubated in Cy2 goat anti-rabbit (1:200; Jackson ImmunoResearch, West Grove, PA) and tetramethylrhodamine isothiocyanate goat anti-mouse (1:200; Jackson ImmunoResearch) secondary antibodies at $37^{\circ} \mathrm{C}$ for $30 \mathrm{~min}$. Coverslips were rinsed (three times) and mounted in Fluor-mount (BDH Laboratory Supplies, Poole, UK) and fluorescence was visualized using a Nikon (Tokyo, Japan) Microphot microscope.

In vitro cell culture. Viable vibratome brain sections were obtained exactly as described above, but BrdU was not injected into mice used for cell culture. Once the $400 \mu \mathrm{m}$ coronal sections were prepared, the ependymal tissue was dissected free from the subependymal tissue and placed into an enzyme solution [aCSF modified to contain high $\mathrm{Mg}^{2+}$ (3.2 $\left.\mathrm{mm} \mathrm{MgCl}_{2}\right)$ and low $\mathrm{Ca}^{2+}\left(0.1 \mathrm{mM} \mathrm{CaCl}_{2}\right), 1.33 \mathrm{mg} / \mathrm{ml}$ trypsin (Sigma), $0.67 \mathrm{mg} / \mathrm{ml}$ hyaluronidase (Sigma), and $0.2 \mathrm{mg} / \mathrm{ml}$ kynurenic acid (Sigma)] for $30 \mathrm{~min}$ at $37^{\circ} \mathrm{C}$ to facilitate dissociation of the cells. The remaining subependymal tissue from this dissected hemisphere was then further dissected free by cutting as thin a layer of cells as possible with microdissection scissors along the contour of the septal side of the ventricle, being careful to sample only where ependyma had been successfully removed. The subependyma is thinner on this side of the brain (one to two cells thick) when compared with the striatal side (two to four cells thick). This subependymal tissue was also placed into the same 

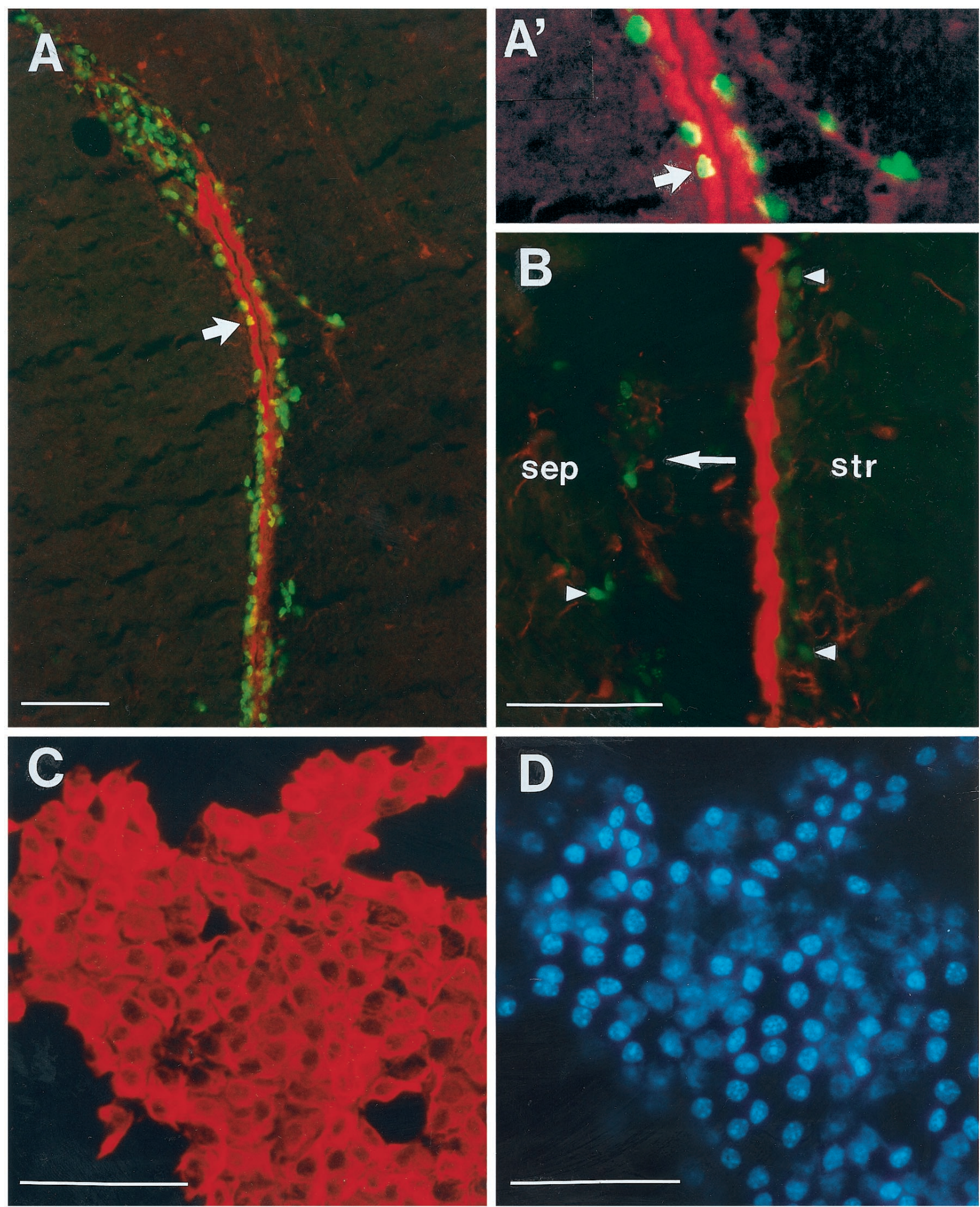

Figure 2. The ependyma can be dissected free of surrounding tissue. $A$, A $14 \mu \mathrm{m}$ coronal section through the lateral ventricle demonstrates that S-100 $\beta$ (red) antibodies selectively stain all of the ependymal cells adjacent to the lateral ventricle and that BrdU ( green) antibodies only stain a subpopulation of the cells in the subependyma. A few cells appear to be double-labeled cells in 14- $\mu \mathrm{m}$-thick sections (yellow, indicated by arrow in $A$ ), but on closer inspection, it is clear that some of the BrdU-labeled nuclei (green) can still be seen beyond the edge of (and thus are distinct from) the S-100 $\beta$-positive ependyma cytoplasmic staining (red) as shown in $A^{\prime}$ (higher magnification of cells indicated in $A$ ). Thus, these apparent double-labeled cells are actually separate cells sitting on top of one another within the $14 \mu \mathrm{m}$ sections. Further support for this conclusion comes from the complete lack of any (even suggestive) double labeling seen in thinner $6 \mu \mathrm{m}$ sections. The same nonoverlapping populations of BrdU ${ }^{+}$subependymal and S-100 $\beta^{+}$ependymal cells were observed after $7 \mathrm{~d}$ of BrdU labeling and then a $31 \mathrm{~d}$ survival. B, From a partially dissected coronal section, S-100 $\beta^{+}$(Figure legend continues) 
enzyme solution in a separate dish. Finally, the contralateral hemisphere had both the ependyma and subependyma removed together by cutting a thin slice along the contour of the septal side of the ventricle. This tissue was also treated separately so that all three tissue groups (ependyma, subependyma, and ependyma plus subependyma) could be evaluated for the generation of clonal aggregates (neurospheres). After $30 \mathrm{~min}$ in the enzyme solution, the tissues were transferred to test tubes and centrifuged at $150 \times g$ for $5 \mathrm{~min}$. Subsequently, the enzyme solution was removed, and serum-free media containing trypsin inhibitor $(15 \mathrm{mg} / \mathrm{ml}$ ovamucoid; Boehringer Mannheim) was added. The tissues were mechanically triturated with fire-polished Pasteur pipettes and centrifuged once more at $150 \times g$ for $5 \mathrm{~min}$. The ovamucoid solution was removed and replaced with chemically defined serum-free media as described previously (Reynolds and Weiss, 1992; Tropepe et al., 1997). Cells from each tissue group were evenly distributed into six wells per group in 24-well culture plates (Nunc, Naperville, IL). Growth factors were used at final concentrations of $10 \mathrm{ng} / \mathrm{ml} \mathrm{FGF} 2$ (human recombinant; Upstate Biotechnology, Lake Placid, NY) and $2 \mu \mathrm{g} / \mathrm{ml}$ heparin (Upstate Biotechnology) or $20 \mathrm{ng} / \mathrm{ml}$ EGF (mouse submaxillary; Upstate Biotechnology). These factors were added to the culture wells of each tissue group so that there were two wells per growth factor condition [EGF, FGF2, or no growth factor (no GF)] in each tissue group. To examine cell differentiation, spheres were plated down onto the plastic of 24-well culture dishes with or without $50 \mu \mathrm{g} / \mathrm{ml}$ laminin (Life Technologies, Gaithersburg, MD) or $15 \mu \mathrm{g} / \mathrm{ml}$ poly-ornithine (Sigma)-coated coverslips and were exposed to 1 or $10 \%$ fetal calf serum (FCS), similar to the approach used in previous studies to examine multipotentiality of stem cells (Reynolds and Weiss, 1992, 1996).

Assessing self-renewal. Spheres were isolated and incubated in an enzyme solution (as above) and subsequently triturated in the presence of ovamucoid until a single cell suspension was obtained. The tissues were then centrifuged at $150 \times g$ and transferred to fresh serum-free solutions as described above.

\section{RESULTS}

\section{Dissection of the ependyma from the subependyma}

Coronal forebrain sections revealed that $\mathrm{S}-100 \beta$ antibodies heavily labeled ependymal cells and BrdU antibodies heavily labeled a subpopulation of subependymal cells (Fig. 2A). Cells double-labeled with antibodies to $\mathrm{S}-100 \beta$ and BrdU were never seen around the adult lateral ventricle, even after $7 \mathrm{~d}$ of administration of BrdU in the drinking water in an attempt to label cells that divide infrequently. Double labeling in $14-\mu \mathrm{m}$-thick sections revealed a few cells that looked to be BrdU- and S- $100 \beta$-positive, however, at higher magnification, it was apparent that the BrdUpositive nuclei were not entirely contained within the S-100 $\beta$ positive cytoplasm (Fig. $2 A, A^{\prime}$ ). The observation of two nonoverlapping populations of cells was further substantiated using $6-\mu \mathrm{m}-$ thick sections in which no double-labeled cells were observed. The ependymal layer could be reliably removed by mechanical dissection without contamination from other cell types. Ependymal tissue dissected from seven different mice was processed for immunocytochemical staining for BrdU and S-100 $\beta$. The dissected ependyma showed positive staining for $\mathrm{S}-100 \beta$ but did not label with anti-BrdU antibodies (Fig. $2 C$ ). However, the remaining portion of the same coronal sections (after the ependymal dissections) from the same animals showed both positive S- $100 \beta$ staining in the ependyma (where it had not been dissected free on the striatal side) and BrdU-stained cells within the subependyma (where the ependyma was removed on the septal side) (Fig. 2B). No S- $100 \beta^{+}$ependymal cells were seen remaining in the region of the lateral ventricle, where the ependyma had been dissected away (Fig. 2B, arrow). Furthermore, all cells that stained with Hoechst 33258 in the dissected ependyma sheet (Fig. 2D) strongly expressed S-100 $\beta$ (Fig. $2 C$ ), suggesting that all labeled cells were of ependymal origin. These results demonstrate that small pieces (sheets) of the ependyma could be reliably dissected free from the subependyma on the septal side of the brain. The maximum number of ependymal cells that could be obtained in these dissections from 3 of the $400 \mu \mathrm{m}$ coronal sections was $\sim 4000$ cells. Because the subependyma is only one to two cells thick on the septal side and because only the regions from which the ependyma was judged to be removed successfully were microdissected further, an approximately similar number of cells for the subependymal tissue was taken. A section of ependyma and subependyma of a similar size was removed together from the contralateral side for tissue culture experiments. The ipsilateral dissection of the ependyma from the subependyma allowed us to determine the location of neural stem cells using the neurosphere assay in vitro.

\section{Ependymal cells proliferate to form spheres in vitro in the absence of exogenous growth factors; subependymal spheres form only in EGF or FGF2}

To determine whether ependymal or subependymal cells could form neurospheres, the dissected and dissociated cells were plated independently in 24-well culture dishes with or without EGF or FGF2. Using the contralateral hemisphere from the same coronal sections of the brain, a comparable region of both ependyma and subependyma also was collected, dissociated, and plated together in the conditions mentioned above. Spheres were generated from dissociated ependymal cells (plated in the absence of subependymal cells) with no exogenous growth factors added (i.e., independent of the presence of exogenous EGF or FGF2). In $\sim 30 \%$ of the wells, the production of at least one sphere per well was observed when these ependymal cells were dissociated and cultured in duplicate in EGF, FGF2, or no GF conditions $(\sim 650$ ependymal cells per well are plated because a maximum number of 4000 cells is distributed evenly into six wells: two EGF, two FGF2, and two no GF). Overall, very few spheres could be generated from ependyma (Fig. 3). Because each well contained only a small number of dissociated ependymal cells, the spheres generated must have been clonally derived. On the other hand, when subependyma (similar low-density cultures) was plated without ependyma, spheres were generated in EGF or FGF2 but were never observed in no GF conditions. The subependymal cells plated without ependymal cells generated spheres of cells reminiscent of neurospheres in $\sim 30 \%$ (FGF2) and $50 \%$ (EGF) of the wells but never generated spheres in no GF conditions. Furthermore, when ependyma and subependyma where plated together, it was observed that the number of spheres increased significantly in the FGF2 condition, to above what

\section{$\leftarrow$}

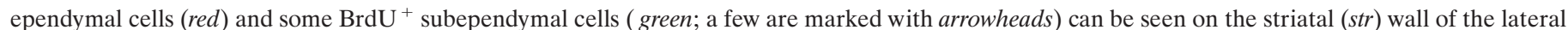

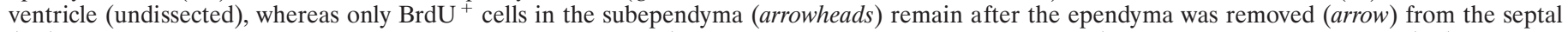

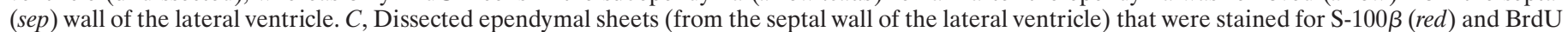

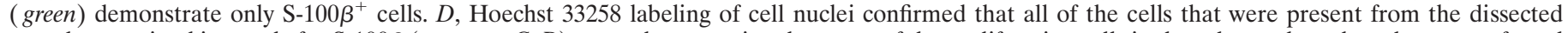

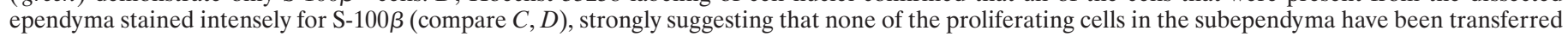

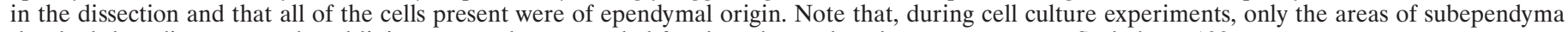
that had the adjacent ependymal lining removed was sampled for the subependymal treatment group. Scale bars, $100 \mu \mathrm{m}$. 


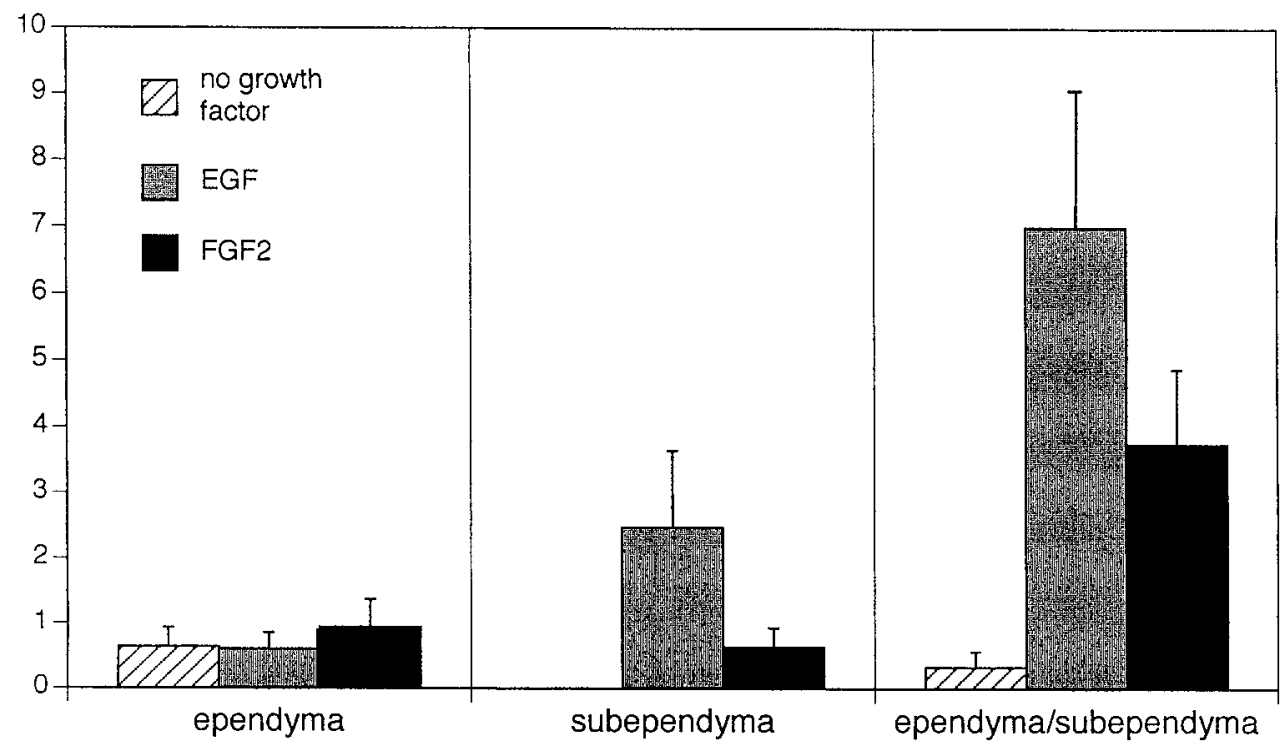

Figure 3. Ependymal spheres form in no exogenous growth factor, and subependymal spheres arise only in EGF or FGF2. The generation of spheres in FGF2 from tissue containing both the ependyma and subependyma exceeds the number of spheres generated by ependymal and subependymal cultures separately (ependyma alone plus subependyma alone < ependyma with subependyma; $p<0.01$ ). A similar, but nonsignificant, trend to increased spheres for the ependymal and subependymal cocultures is seen in EGF, as well. The increased numbers of spheres in cocultures can all be attributed to the generation of additional subependymal (larger, nonciliated) spheres. would be predicted from the simple mathematical addition of the ependyma and subependyma (Fig. 3). All of the increased numbers of spheres observed in the coculture experiments originated from the subependyma based on morphological criteria (see below). Although not significant, a similar facilitative trend for an increase in the number of spheres from the combined ependyma and subependyma cocultures was observed in the EGF condition. In both EGF and FGF2 conditions, subependymal spheres were generated in $70 \%$ of the wells from ependyma and subependyma cocultures. All of the spheres generated in the no GF condition from the ependymal and subependyma cocultures could be attributed (based on morphological criteria) to those generated from the ependyma (see below); this occurred in $\sim 20 \%$ of the wells.

One of the notable differences observed between spheres generated from the ependyma versus those generated from the subependyma was their morphology. Compared with the much larger ( $\sim 500-1000 \mu \mathrm{m}$ in diameter) spheres generated from subependyma alone (Fig. 4A), ependymal spheres were always small, measuring $5-10$ cells in diameter $(<100 \mu \mathrm{m})$ (Fig. $4 B)$. Another very obvious difference between the ependymal spheres and the subependymal spheres was the fact that ependymal spheres were composed of ciliated cells, which caused the sphere to rotate in solution. This allowed us to easily discern the ependymal-derived spheres generated when both tissues (ependyma and subependyma) were cultured together.

In some experiments, undissociated sheets of ependymal cells (estimated to be $200-800$ cells per sheet) were dissected and placed directly into the culture media. These sheets also demonstrated proliferation and formed a thickened sheet of cells in EGF, FGF2, or no GF conditions. In fact, in every condition when ependymal sheets were placed into media (approximately two to three sheets were obtained per $400 \mu \mathrm{m}$ section, and two to three sections were obtained from one brain in at least 15 mice per condition), they were observed to proliferate, independent of the growth factor condition (100\%). Cells proliferated more or less evenly along the entire sheet to form a rope-like structure composed of ciliated cells, which caused the sheet to rotate continuously like the ependymal spheres described earlier. In contrast to the extensive proliferation seen throughout the ependymal sheets, we estimate that $<1 \%$ of the dissociated ependymal cells proliferate enough to form a sphere. These observations suggest that the ability of ependymal cells to proliferate in vitro may depend on the degree of contact that they have with neighboring ependymal cells (i.e., more proliferation is seen in ependymal cells left in an intact sheet than those dissociated into single cells). Some of the nondividing, dissociated cells that remained viable throughout the culture period in FGF2 adopted an elongated, bipolar morphology reminiscent of radial glia (Fig. $4 C$ ), but the majority of nonsphere-forming ependymal cells had a flat and rounded phenotype in all growth factor conditions.

\section{Ependymal spheres do not passage; subependymal spheres do passage}

Spheres derived from the subependyma or the ependyma (in addition to the separate proliferative ependymal sheets) were dissociated into single cells and replated in EGF, FGF2, or no GF conditions. Cells from single subependymal sphere dissociations were able to reproduce multiple new spheres in either EGF or FGF2 but not in no GF conditions. There was no significant difference between the number of secondary spheres generated from single dissociated subependymal spheres derived in FGF2 from subependyma only cultures and the number of secondary spheres generated from single dissociated subependymal spheres derived in FGF2 from ependyma and subependyma cocultures $\left(t_{11}=1.27 ; p>0.05\right)$. When ependymal spheres or sheets were dissociated and replated in any of the conditions, new spheres were never seen, even when cells were followed for up to $21 \mathrm{~d}$. Because the proliferating sheets of ependymal cells were dissociated, we did not expect to see new sheets but rather, if stem cells were present within the proliferating sheets of cells, then we would expect to see new spheres generated (similar to what we observed from dissociated primary subependymal spheres). The sheets were dissociated into single cells, and we never observed new spheres to arise from these dissociated ependymal sheets. Although spheres generated from ependymal cells share some proliferative similarities with previously described neurospheres (Weiss et al., 1996), these spheres do not appear to possess the ability to self-renew (produce secondary spheres similar to the subependymal spheres). These observations suggest that primary ependymal cells can proliferate in vitro, independent of EGF or FGF2, but that it is unlikely that these cells possess one of the cardinal characteristics of stem cells, the ability to self-renew. 

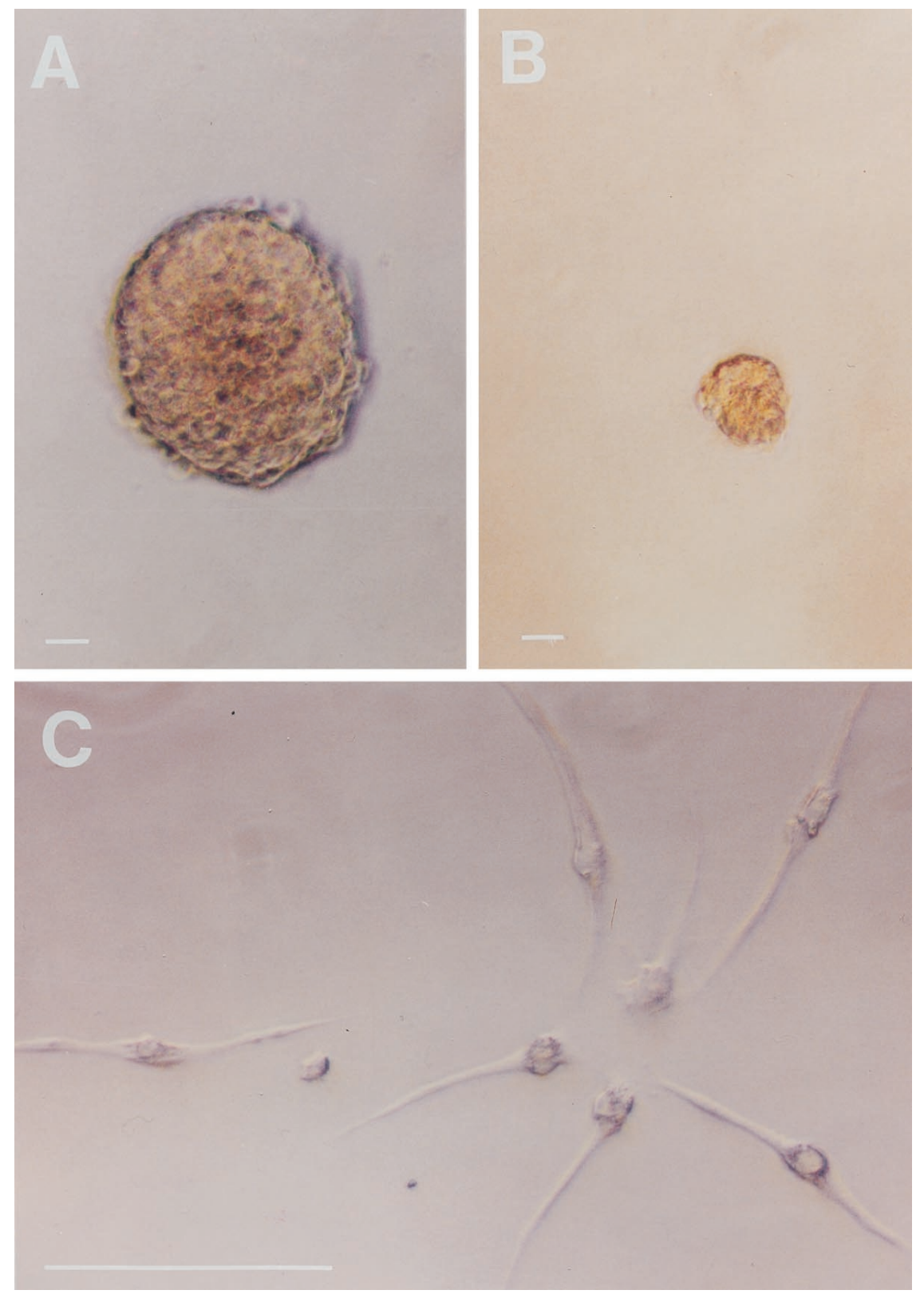

Figure 4. Subependymal $(A)$ and ependymal $(B)$ spheres demonstrate distinct morphologies after $8 \mathrm{~d}$ in vitro. Ependymal spheres were small and measured $<100 \mu \mathrm{m}$ in diameter compared with the larger $(500-$ $1000 \mu \mathrm{m}$ in diameter) spheres generated from subependyma alone. One very obvious difference between the ependymal spheres and the subependymal spheres was the fact that ependymal spheres were composed of ciliated cells, which caused the spheres to rotate in the cell culture media. $C$, A small number of nonsphere-forming ependymal cells derived from a primary dissection adhered to the culture plate and displayed an elongated, bipolar morphology in the presence of FGF2. Scale bars, $100 \mu \mathrm{m}$.

\section{Sphere-forming ependymal cells are not multipotential; sphere-forming subependymal cells are multipotential}

To examine the possibility that the ependymal cells may represent a multipotential precursor cell, spheres generated from ependymal cells were analyzed using immunostaining for the expression of neuronal and glial antigens. Primary subependymal spheres, as well as ependymal spheres, and sheets were plated down into 24-well culture dishes in the presence or absence of either 50 $\mu \mathrm{g} / \mathrm{ml}$ laminin or $15 \mu \mathrm{g} / \mathrm{ml}$ poly-ornithine coated-coverslips and were exposed to 1 or $10 \%$ FCS, similar to the approach used in previous studies to examine the differentiative multipotentiality of adult neural stem cells (Reynolds and Weiss, 1992, 1996). Immunostaining the cells from ependymal spheres for either GFAP and MAP2 demonstrated that the entire population of cells that made up the ependymal sphere was glial in nature $\left(\mathrm{GFAP}^{+}\right)$, independent of the length of time exposed to the plating conditions (periods examined were between 3 and $21 \mathrm{~d}$ with media changes every 6 d) (Fig. 5). Subependymal spheres, on the other hand, demonstrated separate cells that expressed GFAP and MAP2 as has been reported previously for adult forebrain neural stem cell spheres (Reynolds and Weiss, 1992; Gritti et al., 1996). There was no difference between the differentiation of subependymal spheres derived from subependyma only cultures $\left(21 \pm 8.7 \% \mathrm{MAP}^{+}{ }^{+}\right.$neurons and $>50 \% \mathrm{GFAP}^{+}$astrocytes $)$and the differentiation of subependymal spheres derived from ependyma and subependyma cocultures $\left(23 \pm 6.9 \% \mathrm{MAP}^{+}\right.$ neurons and $>50 \% \mathrm{GFAP}^{+}$astrocytes).

\section{DISCUSSION}

The adult forebrain ependymal and subependymal cells both show proliferative potential, but only subependymal cells have neural stem cell characteristics as determined by their selfrenewing capability (generating secondary spheres) and their ability to clonally give rise to neurons and glia, the characteristics demonstrated previously for adult forebrain neural stem cells (Reynolds and Weiss, 1992; Gritti et al., 1996; Morshead et al., 

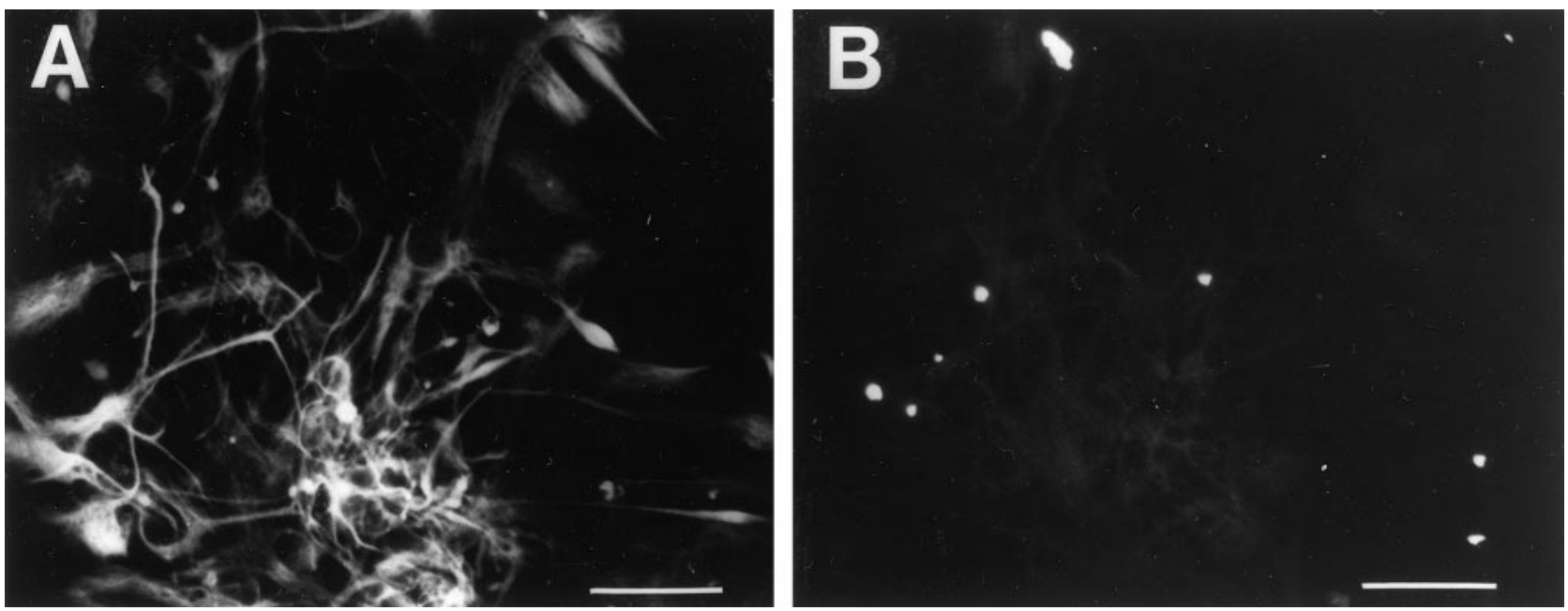

Figure 5. Ependymal spheres produce differentiated ependymal cells as revealed by expression of GFAP. $A$, GFAP ${ }^{+}$immunostaining of cells from a differentiated ependymal sphere originally grown in EGF and subsequently plated in 1\% FBS for 1 week. $B$, The same field stained with MAP2 antibodies revealed that no neurons were derived from the differentiated ependymal sphere. Bright spots are noncellular, nonspecific fluorescence. Scale bars, $50 \mu \mathrm{m}$.

1994). The isolated ependymal cells were observed to proliferate and form sphere-like structures, albeit with different morphological characteristics than the previously described neurospheres (Reynolds and Weiss, 1992; Weiss et al., 1996), which as shown here are derived from subependymal cells. The ependymal spheres were small compared with subependymal spheres and were always composed of ciliated cells. Similarly, sheets of ependymal cells, which were plated directly into cell culture media without dissociation, were also made up of actively dividing ciliated cells. Cells within ependymal spheres or sheets expressed GFAP, but not MAP2, when plated down in culture conditions that encourage the cells from subependymal spheres to differentiate into neurons and astrocytes. Ependymal cells appear to retain their in vivo ependymal phenotype (i.e., immunostaining characteristics and morphology) in vitro, even after going through many cell divisions. Thus, the most parsimonious interpretation of the clonally derived ependymal sphere is that single ependymal cells divided to give rise to more ependymal cells. Although the morphology of some of the ependymal cells from primary dissection was reminiscent of that of radial glial cells, it remains to be determined whether some of these ependymal cells are differentiating into true radial glial cells in vitro or whether the adhesive substrates used in the present study are permissive for an elongated, bipolar morphology (especially in FGF2). Furthermore, because only a small number of ependymal cells demonstrated this characteristic morphology, these cells may correspond to the small percentage of tanycytes that are present within the ependymal layer (Bruni et al., 1985; Gould et al., 1990; Doetsch et al., 1997).

Single subependymal neural stem cells generated spheres of undifferentiated cells in FGF2 or EGF but not in the absence of exogenous growth factors, such as the primary ependymal spheres. A small number of cells from each dissociated subependymal-derived sphere could generate new (secondary) spheres in the presence of either EGF or FGF2, whereas the majority of cells from the spheres were shown to differentiate into neurons and glia, as described previously (Reynolds and Weiss, 1992, 1996), demonstrating the self-renewal and multipotential nature of the subependymal stem cells. In contrast, ependymal- derived spheres could be generated in the absence of exogenous growth factors but could not be passaged. After differentiation, ependymal sphere cells expressed only GFAP (astrocytic) immunoreactivity and were negative for MAP2 (neuronal) immunoreactivity. The apparent growth factor-independent proliferation of isolated ependymal cells (and especially of ependymal sheets) may indicate that ependymal cells can autonomously regulate (perhaps through an autocrine release of mitogens) their mitotic activity. However, we cannot exclude the possibility that the ependymal cells proliferate in response to exogenous insulin that is present in the serum-free culture media. Ependymal cells are known to express insulin-like growth factor receptors (IGFR-1) (Stenvers et al., 1994).

Based on the present findings and previous work showing the necessity for the subependyma/ependyma to be present in brain dissections to generate neurospheres (Morshead et al., 1994), we conclude that forebrain neural stem cells reside solely within the adult forebrain subependyma and not the ependyma. Furthermore, a more refined interpretation of the identity of the neural stem cell and more generally of sphere-forming cells around the lateral ventricle can be proposed according to a detailed cytoarchitectural model of the adult mammalian forebrain germinal zone.

Considering first the ependyma, Doetsch et al. (1997) identified a small proportion of $\mathrm{GFAP}^{+}$cells within the ependyma as tanycytes according to their morphology (because of their lateral extensions, luminally displaced microvilli, and lack of cilia), and these cells did not incorporate tritiated thymidine ( $\left[{ }^{3} \mathrm{H}\right]$ thy). The ependymal cells lining the lateral ventricles are also mitotically quiescent and express GFAP, vimentin, and nestin. Therefore, the cells within the ependyma identified as "quiescent" and, hence, potential candidates for the relatively quiescent neural stem cells (Morshead et al., 1994, 1998), were the tanycytes and ependymal cells (Doetsch et al., 1997). It was proposed that ependymal cells (or a subset of the ependymal cells) might correspond to the stem cells because of their relatively high expression of nestin (a neural precursor cell marker) (Doetsch et al., 1997). However, the present results exclude ependymal cells 
Table 1. Growth factor responsiveness, morphology, capacity to self-renew, and differentiation potential of ependyma and subependyma spheres

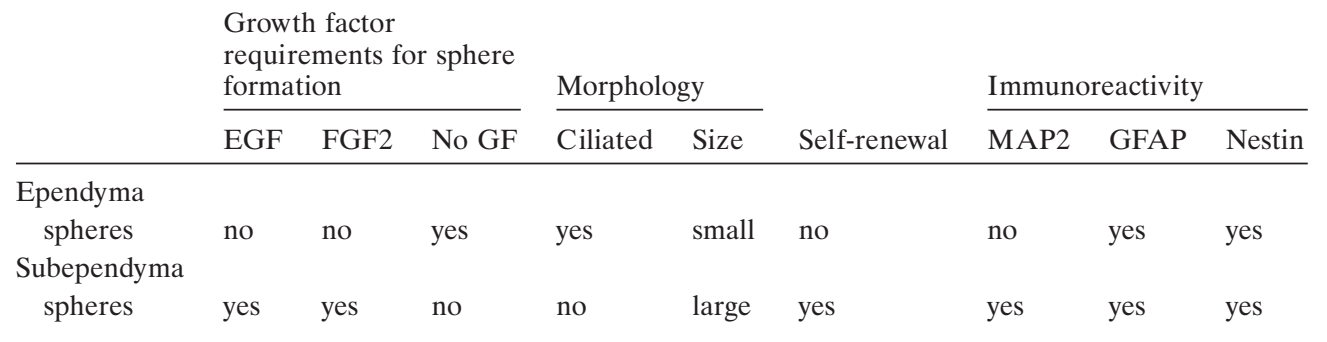

Summary chart illustrating the fundamentally different characteristics of the spheres generated from ependymal cultures versus subependymal cultures. The growth factor requirements for sphere formation are such that the absolute numbers of spheres generated from ependymal cultures plated in EGF or FGF2 are no different from the numbers of spheres generated from ependymal cultures plated in no GF. The presence of EGF or FGF2 is absolutely necessary for sphere formation from subependymal cultures. Details are described in the text.

as candidate stem cells because of their inability to demonstrate stem cell characteristics when isolated separately from the subependyma, whereas a small subset of subependymal cells were shown here to demonstrate neural stem cell characteristics. Because tanycytes are normally embedded within the ependymal layer (contacting ventricular lumen) (Doetsch et al., 1997), these cells were likely isolated together with other ependymal cells in the present microdissection procedures and thus cannot be the neural stem cells. It is formally possible that the nonciliated tanycytes gave rise to the ependymal spheres (the putative ependymal precursors discussed above); however, a majority of cells within the spheres were ciliated. Nevertheless, the ependymal spheres did not demonstrate neural stem cell characteristics.

Second, Doetsch et al. (1997) have identified several different cell types that coexist within the subependymal population. Type A cells correspond to dividing neuronal progenitor cells (PSA$\mathrm{NCAM}^{+}, \mathrm{TuJ} 1^{+}$, nestin ${ }^{+}$) that migrate tangentially from the rostral subependymal zone to the olfactory bulb (Lois et al., 1996). Type A cell proliferation in the dorsolateral corner of the subependyma appears to be dependent on TGF- $\alpha$ (Tropepe et al., 1997), suggesting that these cells also express the EGF receptor (Morshead et al., 1994; Okano et al., 1996). Type B cells (mitotically quiescent type B1 and mitotically active type B2) are glial-like cells that ensheathe neuronal progenitor cells (type A) that migrate from the subependyma to the olfactory bulb (Lois and Alvarez-Buylla, 1993; Doetsch and Alvarez-Buylla, 1996; Doetsch et al., 1997). Type B cells express GFAP, vimentin, and nestin. Type $\mathrm{C}$ cells are undifferentiated, mitotically active cells that express only nestin. These cells are thought to correspond to the constitutively proliferating progenitor cells and not to the neural stem cells because of their highly proliferative behavior (Morshead et al., 1994; Doetsch et al., 1997; Garcia-Verdugo et al., 1998). Although the C cell was identified as highly proliferative, because of the fact that it is undifferentiated (a characteristic often associated with stem cells), it remains possible that a subset of the C cells (mitotically quiescent) could represent the endogenous stem cells. Doetsch et al. (1997) showed that some of the type $\mathrm{C}$ cells identified are actively proliferating using a single pulse of $\left[{ }^{3} \mathrm{H}\right]$ thy. However, it is highly unlikely that a single pulse of $\left[{ }^{3} \mathrm{H}\right]$ thy would label stem cells with a cell cycle time of $15 \mathrm{~d}$ or more (assuming the S-phase remains $\sim 4 \mathrm{hr}$ ) because the majority of $\left[{ }^{3} \mathrm{H}\right]$ thy is available for only $1-2 \mathrm{hr}$ after administration, and the stem cells within this region make up only a small percentage of the entire subependymal population in a mouse forebrain (estimated to be $\sim 0.4 \%$ ) (Morshead et al., 1998). Furthermore,
Doetsch et al. (1997) did not report what percentage of C cells were labeled with $\left[{ }^{3} \mathrm{H}\right]$ thy. Thus, it is conceivable that a subpopulation of relatively quiescent $\mathrm{C}$ cells could represent the neural stem cells. Another candidate for the neural stem cell appears to be the mitotically quiescent type B1 cell, despite the fact that the type B1 cells express GFAP (as well as nestin and vimentin) and appear differentiated. This is consistent with the suggestion of Alvarez-Buylla and colleagues (Garcia-Verdugo et al., 1998) who have postulated that the type B1 cell is a candidate for the endogenous neural stem cell. It is also consistent with results from developing avian and mammalian brain that suggest that a glial cell type (the radial glial cell) may be the stem cell (AlvarezBuylla et al., 1990; Gray and Sanes, 1992; Goldman et al., 1996). On the other hand, it is some of the adult ependymal cells themselves that appear to form radial cells in vitro in the presence of FGF2. Moreover, because the neural stem cells in the adult forebrain are estimated to make up $0.2-0.4 \%$ of all subependymal cells (Morshead et al., 1998), lower than the frequency of any of the single cell types characterized by Doetsch et al. (1997), it remains possible that a small subpopulation of type $C$ cells (as discussed above) or some minor cell type unrecognized morphologically represents the true neural stem cell in the adult subependyma.

This paper reports the microdissection of the ependyma from the subependyma and the subsequent generation of two distinct populations of spheres that can be separated on the basis of their growth factor responsiveness, their morphology, their capacity to self-renew, and their differentiation potential (Table 1). The ependyma only dissections did not generate self-renewing, multipotential spheres and hence are not, by definition, neural stem cells. Recently, Johansson et al. (1999) reported exactly the opposite conclusion, that the ependyma is the in vivo source of neural stem cells. Perhaps the most important difference in the culture conditions of the two studies is that it was necessary for Johansson et al. (1999) to add conditioned media from primary cultures to dissociated primary spheres to get secondary sphere formation and hence illustrate self-renewal. Certainly, the subependymal spheres in the present and previous reports (Reynolds and Weiss, 1992, 1996) do not require conditioned media for passaging. The in vivo injection of DiI into the lateral ventricles that Johansson et al. (1999) used to specifically label the ependymal cells does not appear to exclusively label ependymal cells (their Fig. 1D), especially given the possibility of transfer to the subependymal cells in vivo or in vitro after dissection and cultur- 
ing. Not only does the labeling technique makes it difficult to ascertain whether ependymal cells have been exclusively labeled, but the conclusions of Johansson et al. (1999) are further complicated by the culturing and subsequent bulk passaging of both populations of cells (ependyma and subependyma together) to study the self-renewal and multipotentiality of spheres. We suggest that, although ependymal cells will proliferate to form spheres, the spheres that self-renew and show multipotential differentiation capacity derive from the adult subependyma only. To address definitively whether ependymal cells are stem cells, it would be useful to test the passageability of the single spheres that Johansson et al. (1999) derive in single wells from single ciliated ependymal cells, as well as to examine the differentiation potential of these single ependymal spheres. The prediction from the present work would be that the spheres derived from single ciliated ependymal cells would not display the cardinal stem cell properties of self-renewal and multipotentiality.

The embryonic forebrain $\mathrm{VZ}$ arises earlier in development and gives rise to the embryonic SVZ (Sturrock and Smart, 1980; Altman and Bayer, 1990; Takahashi et al., 1996; Reznikov et al., 1997). If the neural stem cell is the earliest cell (or one of the earliest cells) to arise in the forebrain, then initially it must be present in the VZ because recent evidence suggests that an FGF2-responsive neural stem cell can be isolated in vitro from the mouse embryonic day 8.5 anterior neural plate (Tropepe et al., 1999). At this time in development, there are only presumptive VZ cells before neural tube closure. Given the present results showing that the neural stem cell exists solely in the forebrain subependyma in the adult, then at least in terms of the stem cell population, the embryonic $\mathrm{VZ}$ gives rise to the adult subependyma. The cells of the embryonic VZ differentiate into the cuboidal epithelial cells of the ependymal lining (Takahashi et al., 1996). However, in light of the present data, the VZ cells that differentiate into the ependymal cells cannot be the neural stem cells [which persist throughout the life of the animal (Tropepe et al., 1997)]. The neural stem cells in the embryonic VZ must migrate into the embryonic SVZ (which eventually will occupy the portion the adult subependyma) before the remaining progenitors in the embryonic VZ become ependymal cells. In other words, the embryonic SVZ, like the neural crest, may only be a transient cell population (containing progenitor cells that generate many neurons and glia when they are required in the perinatal period), and it is really the neural stem cells from the earliest embryonic forebrain VZ that migrate out and form what will become the permanent adult forebrain subependyma.

\section{REFERENCES}

Altman J, Bayer SA (1990) Horizontal compartmentalization in the germinal matrices and the intermediate zone of the embryonic rat cerebral cortex. Exp Neurol 107:36-47.

Alvarez-Buylla A, Theelen M, Nottebohm F (1990) Proliferation "hot spots" in adult avian ventricular zone reveal radial cell division. Neuron 5:101-109.

Bernstein JJ (1986) Ependymal formation in adult rat spinal cord after transplantation of fetal cerebral cortex homographs. J Neurosci Res 15:481-490.

Bruni JE, Del Bigio MR, Clattenburg RE (1985) Ependyma: normal and pathological. A review of the literature. Brain Res Rev 9:1-19.

Craig CG, Tropepe V, Morshead CM, Reynolds BA, Weiss S, van der Kooy D (1996) In Vivo growth factor expansion of endogenous subependymal neural precursor cell populations in the adult mouse brain. J Neurosci 16:2649-2658.
Doetsch F, Alvarez-Buylla A (1996) Network of tangential pathways for neuronal migration in adult mammalian brain. Proc Natl Acad Sci USA 93:14895-14900.

Doetsch F, Garcia-Verdugo JM, Alvarez-Buylla A (1997) Cellular composition and three-dimensional organization of the subventricular germinal zone in the adult mammalian brain. J Neurosci 17:5046-5061.

Franklin KBJ, Paxinos G (1997) The mouse brain in stereotaxic coordinates. San Diego: Academic.

Garcia-Verdugo JM, Doetsch F, Wichterle H, Lim DA, Alvarez-Buylla A (1998) Architecture and cell types of the adult subventricular zone: in search of the stem cells. J Neurobiol 36:234-248.

Goldman SA, Zukhar A, Barami K, Mikawa T, Niedzwiecki D (1996) Ependymal/subependymal zone cells of postnatal and adult songbird brain generate both neurons and nonneuronal siblings in vitro and in vivo. J Neurobiol 30:505-520.

Gould SJ, Howard S, Papadaki L (1990) The development of ependyma in the human fetal brain: an immunohistological and electron microscopic study. Dev Brain Res 55:255-267.

Gray GE, Sanes JR (1992) Lineage of radial glia in the chiken optic tectum. Development 114:271-283.

Gritti A, Parati EA, Cova L, Frolichsthal P, Galli R, Wanke E, Faravelli L, Morassutti DJ, Roisen F, Nickel DD, Vescovi AL (1996) Multipotential stem cells from the adult mouse brain proliferate and self-renew in response to basic fibroblast growth factor. J Neurosci 16:1091-1100.

Johansson CB, Momma S, Clarke DL, Risling M, Lendahl U, Frisen J (1999) Identification of a neural stem cell in the adult mammalian central nervous system. Cell 96:25-34.

Kuhn HG, Dickinson-Anson H, Gage FH (1996) Neurogenesis in the dentate gyrus of the adult rat: age-related decrease of neuronal progenitor proliferation. J Neurosci 16:2027-2033.

Lendahl U, Zimmerman LB, McKay RDG (1990) CNS stem cells express a new class of intermediate filament protein. Cell 60:585-595.

Lois C, Alvarez-Buylla A (1993) Proliferating subventricular zone cells in the adult mammalian forebrain can differentiate into neurons and glia. Proc Natl Acad Sci USA 90:2074-2077.

Lois C, Garcia-Verdugo JM, Alvarez-Buylla A (1996) Chain migration of neuronal precursors. Science 271:978-981.

Luskin MB (1993) Restricted proliferation and migration of postnatally generated neurons derived for the forebrain subventricular zone. Neuron 11:173-189.

Matsuo A, Tooyama I, Isobe S, Oomura Y, Akiguchi I, Hanai K, Kimura J, Kimura H (1994) Immunohistochemical localization in the rat brain of an epitope corresponding to the fibroblast growth factor receptor-1. Neuroscience 60:49-66.

Morshead CM, van der Kooy D (1992) Postmitotic death is the fate of constitutively proliferating cells in the subependymal layer of the adult mouse brain. J Neurosci 12:249-256.

Morshead CM, Reynolds BA, Craig CG, McBurney MW, Staines WA, Morassutti D, Weiss S, van der Kooy D (1994) Neural stem cells in the adult mammalian forebrain: a relatively quiescent subpopulation of subependymal cells. Neuron 13:1071-1082.

Morshead CM, Craig CG, van der Kooy D (1998) In vivo clonal analyses reveal the properties of endogenous neural stem cell proliferation in the adult mammalian forebrain. Development 125:2251-2261.

Okano HJ, Pfaff DW, Gibbs RB (1996) Expression of EGFR-, p75NGFR-, and PSTAIR (cdc2)-like immunoreactivity by proliferating cells in the adult rat hippocampal formation and forebrain. Dev Neurosci 18:199-209.

Reynolds BA, Weiss S (1992) Generation of neurons and astrocytes from isolated cells of the adult mammalian central nervous system. Science 255:1707-1710.

Reynolds BA, Weiss S (1996) Clonal and population analyses demonstrate that an EGF-responsive mammalian embryonic CNS precursor is a stem cell. Dev Biol 175:1-13.

Reynolds BA, Tetzlaff W, Weiss S (1992) A multipotent EGFresponsive striatal embryonic progenitor cell produces neurons and astrocytes. J Neurosci 12:4565-4574.

Reznikov K, Acklin SE, van der Kooy D (1997) Clonal heterogeneity in the early embryonic rodent cortical germinal zone and the separation of subventricular from ventricular zone lineages. Dev Dyn 210:328-343.

Richards LJ, Kilpatrick TJ, Bartlett PF (1992) De novo generation of neuronal cells from the adult mouse brain. Proc Natl Acad Sci USA 89:8591-8595.

Sarnat HB (1995) Ependymal reactions to injury. A review. J Neuropath Exp Neurol 54:1-15. 
Smart I (1961) The subependymal layer of the mouse brain and its cell production as shown by radioautography after thymidine- $\mathrm{H}^{3}$ injection. J Comp Neurol 116:325-347.

Stenvers KL, Zimmermann EM, Gallagher M, Lund PK (1994) Expression of insulin-like growth factor binding protein-4 and -5 mRNAs in adult rat forebrain. J Comp Neurol 339:91-105.

Sturrock RR, Smart IHM (1980) A morphological study of the mouse subependymal layer from embryonic life to old age. J Anat 130:391-415.

Takahashi T, Nowakowski RS, Caviness Jr VS (1996) Interkinetic and migratory behavior of a cohort of neocortical neurons arising in the early embryonic murine cerebral wall. J Neurosci 16:5762-5776.
Tropepe V, Craig CG, Morshead CM, van der Kooy D (1997) Transforming growth factor- $\alpha$ null and senescent mice show decreased neural progenitor cell proliferation in the forebrain subependyma. J Neurosci 17:7850-7859.

Tropepe V, Sibilia M, Ciruna BG, Rossant J, Wagner EF, van der Kooy D (1999) Distinct neural stem cells proliferate in response to EGF and FGF2 in the developing mouse telencephalon. Dev Biol 208:166-188.

Weiss S, Reynolds BA, Vescovi AL, Morshead CM, Craig CG, van der Kooy D (1996) Is there a neural stem cell in the mammalian forebrain? Trends Neurosci 19:387-393.

Zamboni L, de Martino C (1967) Buffered acid formaldehyde: a new rapid fixative for electron microscopy. J Cell Biol 148A:35-41. 